\title{
Effect of cooling rate on the crystallization behavior of perovskite in high titanium-bearing blast furnace slag
}

\author{
Lu Liu, Mei-long Hu, Chen-guang Bai, Xue-wei Lü, Yu-zhou Xu, and Qing-yu Deng \\ College of Materials Science and Engineering, Chongqing University, Chongqing 400044, China \\ (Received: 19 November 2013; revised: 9 April 2014; accepted: 10 April 2014)
}

\begin{abstract}
The effect of cooling rate on the crystallization of perovskite in high Ti-bearing blast furnace (BF) slag was studied using confocal scanning laser microscopy (CSLM). Results showed that perovskite was the primary phase formed during the cooling of slag. On the slag surface, the growth of perovskite proceeded via the successive production of quasi-particles along straight lines, which further extended in certain directions. The morphology and structure of perovskite was found to vary as a function of cooling rate. At cooling rates of 10 and 30 $\mathrm{K} / \mathrm{min}$, the dendritic arms of perovskite crossed obliquely, while they were orthogonal at a cooling rate of $20 \mathrm{~K} / \mathrm{min}$ and hexagonal at cooling rates of 40 and $50 \mathrm{~K} / \mathrm{min}$. These three crystal morphologies thus obtained at different cooling rates respectively corresponded to the orthorhombic, cubic and hexagonal crystal structures of perovskite. The observed change in the structure of perovskite could probably be attributed to the deficiency of $\mathrm{O}^{2-}$, when $\mathrm{Ti}_{2} \mathrm{O}_{3}$ was involved in the formation of perovskite.
\end{abstract}

Keywords: blast furnace slag; perovskite; crystallization; cooling rate

\section{Introduction}

China has abundant titanium resources, about $90 \%$ of which exist as vanadium-titanium bearing magnetite, mostly in deposits found around the Panzhihua-Xichang area in the southwestern part of China. Currently, blast furnace (BF) smelting of iron concentrate ores is the main process to adopt for utilizing these resources. However, the BF process is not efficient to collect titanium resources, as approximately $54 \%$ of titanium in the raw ores is collected into iron ore concentrates and finally enriches in blast furnace slag $\left(\mathrm{TiO}_{2}, 22 \mathrm{wt} \%\right.$ to $\left.23 \mathrm{wt} \%\right)$. Consequently, the extraction of titanium from high titanium-bearing BF slag becomes a challenging task. Moreover, the slag formed in this process is not suitable for use in the manufacturing of cement [1]. As a result, more than $6 \times 10^{7} \mathrm{t}$ of slag has been stacked unattended, which not only leads to environmental pollution but also remains to be an undesirable wastage of resources. Thus, the extraction of valuable secondary titanium resources from high Ti-bearing BF slag and the effective use of waste slag remain to be a serious problem in China.

The comprehensive use of titanium-bearing BF slag has aroused wide concern since 1980 but none of the proposed techniques is easy to put into industrial and commercial use [2-9]. However, green extractive processes of titanium component such as the perovskite-based $\mathrm{Ti}$ extraction process and the rutile-based Ti extraction process show a bright prospect [10-12]. The rutile-based $\mathrm{Ti}$ extraction process generates more low activity waste slag, which is also unsuitable for use in cement making [12]. Perovskite crystallizes readily and contains more than $60 \% \mathrm{Ti}$ of the slag. Therefore, enriching titanium in perovskite is considered to be a suitable choice for the current issue [10]. Besides, the separated perovskite phase can also be used as a raw material for the titanium pigment industry, and the tailing can be used as a building material [13]. Although the perovskite-based Ti extraction process offers the advantages of small secondary pollution and low cost, the perovskite yield is rather low owing to the adverse effects of fine and uneven perovskite grains on the mineral separation. In the perovskite-based extraction process, the efficacy of mineral 
separation is greatly influenced by the crystalline volume and crystallinity of the perovskite phase. Therefore, this process often demands reasonable and effective heat treatment conditions. Thus far, several studies have analyzed the kinetics of precipitation and the crystal growth of perovskite phase [1,14-16]. However, to the best of our knowledge, the effect of cooling rate on the crystallization of perovskite has been rarely reported in the literature.

In our previous work reported elsewhere, we analyzed the integrated crystallization of perovskite in high Ti-bearing BF slag at a specific cooling rate of $30 \mathrm{~K} / \mathrm{min}$ by using confocal scanning laser microscopy (CSLM) [17]. According to that study, the growth of perovskite proceeds via a specific growth path, as shown in Fig. 1. In the present study, we have investigated the effect of cooling rate on the nonisothermal crystallization of perovskite in high Ti-bearing slag by using CSLM.

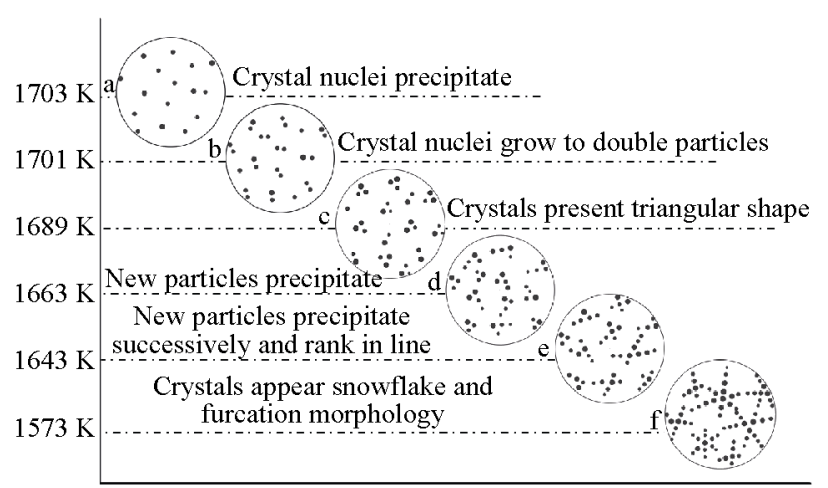

Fig. 1. Schematic representation illustrating the different stages of perovskite crystallization at the cooling rate of 30 $\mathrm{K} / \mathrm{min}$, as observed by using confocal scanning laser microscopy. Perovskite crystals precipitate at $1703 \mathrm{~K}$ and subsequently grow as three particles, which form a triangle. As the temperature is decreased, the growth of perovskite proceeds via the successive appearance of particles along the extension of the triangle, and finally present snowflake and furcationshaped morphologies.

\section{Experimental}

\subsection{Materials and sample preparation}

Herein, high Ti-bearing slag was designed based on industrial slag, the composition of which is shown in Table 1. The slag was prepared by pre-melting $100 \mathrm{~g}$ of a chemical reagent powder mixture consisting of reagent grade $\mathrm{CaO}$ (98\%), $\mathrm{MgO}(98 \%), \mathrm{SiO}_{2}(99 \%), \mathrm{TiO}_{2}(99 \%)$, and $\mathrm{Al}_{2} \mathrm{O}_{3}$ (98\%) powders with the composition shown in Table 1. The mixture thus obtained was dried at $393 \mathrm{~K}$ for $6 \mathrm{~h}$. Following that, the mixture was transferred to a molybdenum crucible (inner diameter of $50 \mathrm{~mm}$ and height of $80 \mathrm{~mm}$ ) and heated to $1773 \mathrm{~K}$ at a heating rate of $300 \mathrm{~K} / \mathrm{h}$ in a $\mathrm{MoSi}_{2}$ furnace under argon atmosphere. The heated mixture was maintained at the designated temperature for $1 \mathrm{~h}$ to obtain a homogenized slag. After melting, the slag was cooled in water and made into small slag samples of $7 \mathrm{~mm}$ in diameter and 3 $\mathrm{mm}$ in height for performing CSLM experiments. The slag was also analyzed by X-ray fluorescence spectroscopy (XRF), and the corresponding result is shown in Table 1.

Table 1. Chemical composition of industrial slag and experimental synthesized slag

$\mathrm{wt} \%$

\begin{tabular}{ccccccccc}
\hline Slag type & $\mathrm{TiO}_{2}$ & $\mathrm{CaO}$ & $\mathrm{SiO}_{2}$ & $\mathrm{Al}_{2} \mathrm{O}_{3}$ & $\mathrm{MgO}$ & $\mathrm{MoO}_{3}$ & Total \\
\hline Industrial slag & 22.34 & 26.96 & 24.21 & 14.35 & 8.32 & 0 & 96.18 \\
$\begin{array}{c}\text { Synthesized slag } \\
\begin{array}{c}\text { Composition, as } \\
\text { analyzed using XRF }\end{array}\end{array}$ & 22.00 & 28.80 & 26.20 & 14.00 & 8.00 & 0 & 100.00 \\
\hline
\end{tabular}

Note: In XRF result, the trace impurities (Fe, K, P, Cr, C, and N) were ignored and the major species were normalized to give a total of $100 \%$. It was assumed that $\mathrm{MoO}_{3}$ had little effect on the experiments.

\subsection{CSLM experiment}

In the present study, the perovskite crystallization behavior was observed in situ by using CSLM equipped with an infrared furnace (VL2000DX, Lasertec). Compared with the conventional methods of studying the crystallization process, such as quenching followed by microscopy, or hot-stage microscopy, CSLM is a new advanced technology that offers the advantages of a higher resolution and real-time in situ observations of transient phenomena at higher temperatures (up to $1973 \mathrm{~K}$ ) [18-19]. Despite these advantages, CSLM has rarely been used for studying the complex melting and solidification behavior of slag.

In the typical experiment, the slag samples were cleaned by ultrasonication, prior to CSLM analysis. The cleaned slag was then placed in a platinum crucible (inner diameter of 8 $\mathrm{mm}$ and height of $5 \mathrm{~mm}$ ) that was placed on a platinum holder in an infrared furnace. Prior to heating, the infrared furnace was evacuated and back-filled with argon $(\mathrm{Ar}>$ $99.999 \%$ ) alternately thrice, in order to ensure complete removal of air from the furnace. The moisture and oxygen contents in the argon were removed by using a purifier provided with the CSLM. Subsequently, the slag sample in the crucible was heated to $1773 \mathrm{~K}$ at a fixed heating rate of 300 $\mathrm{K} / \mathrm{min}$. The slag was maintained at that temperature for 5 min, followed by cooling down to $1373 \mathrm{~K}$ at a certain cooling rate (Fig. 2). The experimental cooling rates were varied 
from 10 to $50 \mathrm{~K} / \mathrm{min}$. The temperature was measured by using a B-type thermocouple welded to the bottom of the platinum holder. The temperature accuracy of the CSLM was confirmed by melting experiments of pure copper (melting point: $1356 \mathrm{~K}$ ) and pure nickel (melting point: 1726 K). Fig. 3 shows the schematic diagram of the experimental apparatus with the sample. The entire process of crystallization as a function of decreasing temperature was recorded in situ using the computer interfaced with the CSLM. Furthermore, the polished surfaces of the cooled samples were examined using a scanning electron microscope (SEM, TESCAN VEGA II) in the back-scattered electron (BSE) mode. The chemical composition and phase of the samples were analyzed by using an energy dispersive X-ray spectrometer (EDS, Oxford INCA Energy 350) equipped with the SEM and X-ray diffraction (XRD: D/max 2500PC), respectively.

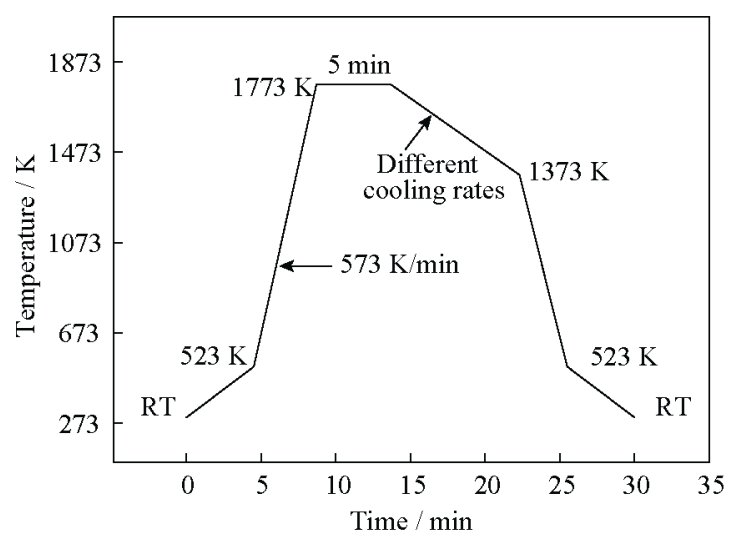

Fig. 2. Temperature profile of the CSLM experiment.

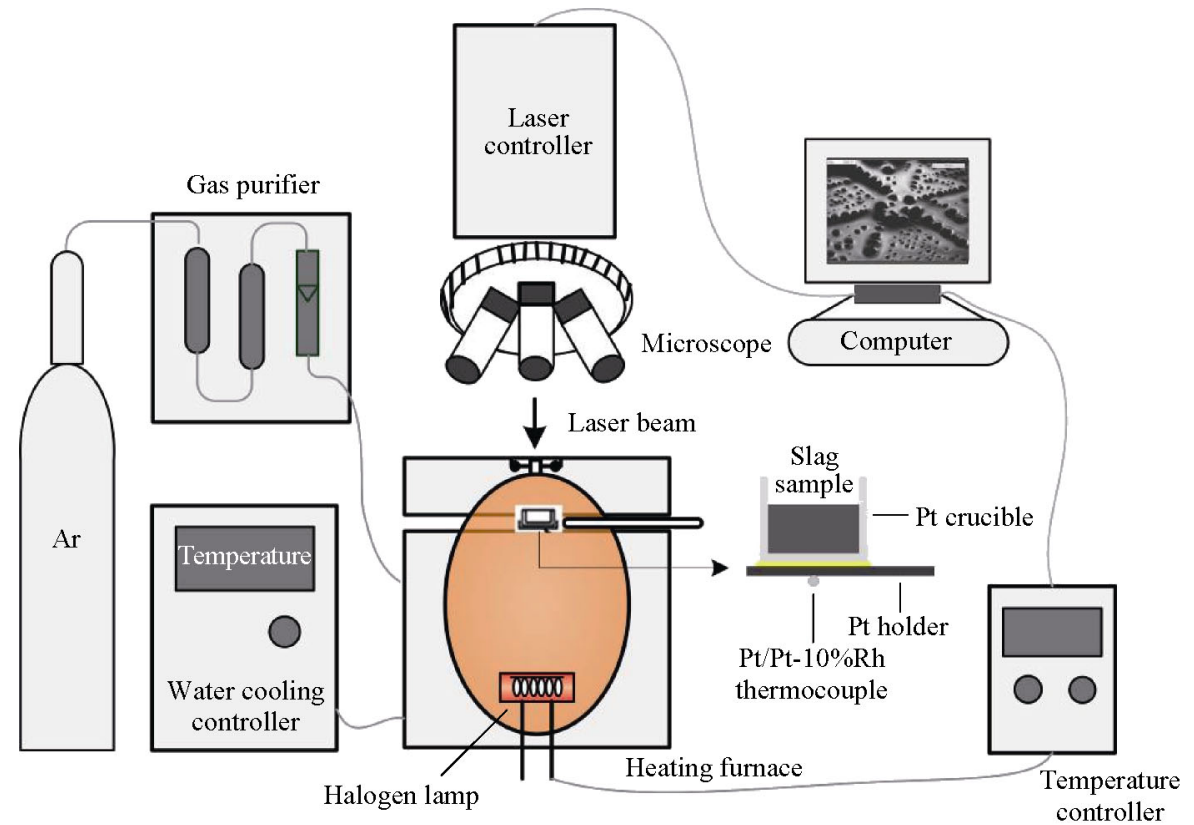

Fig. 3. Schematic diagram of the CSLM apparatus and the sample.

\section{Results}

\subsection{Crystallization of the slag, as observed by using CSLM}

In principle, the surface of the liquid slag keeps fluctuating due to the effect of surface tension driven flow. Therefore, in the early stages of the solidification process, crystals moved in and out of the viewing field, following the movement of liquid slag. Figs. 4-8 show the crystallization of the slag at different cooling rates. As is seen, the slag continues to remain as liquid until above $1733 \mathrm{~K}$, as evidenced from the liquid phase presented in bright white color.

In the case of the crystallization process corresponding to the cooling rate of $10 \mathrm{~K} / \mathrm{min}$, crystals begin to appear as quasi-particles at $1733 \mathrm{~K}$. Initially, we could observe one quasi-particle, following which new quasi-particles appear successively in the opposite directions along a straight line with the first quasi-particle, facilitating the crystal growth (Figs. 4(a)-4(d)). At temperatures below $1703 \mathrm{~K}$, as the cooling continues, more crystals begin to appear with the successive formation of quasi-particles in straight lines. Consequently, the crystals continue to coarsen, while the amount of the liquid phase in the system continues to decrease (Figs. 4(e)-4(1)).

Meanwhile, when the slag is cooled at $20 \mathrm{~K} / \mathrm{min}$, the primary phase appears as three quasi-particles at $1719 \mathrm{~K}$ (Fig. 5(a)) and moves out of the viewing field. Later on, larger sized crystals appear below $1703 \mathrm{~K}$. The crystals have 


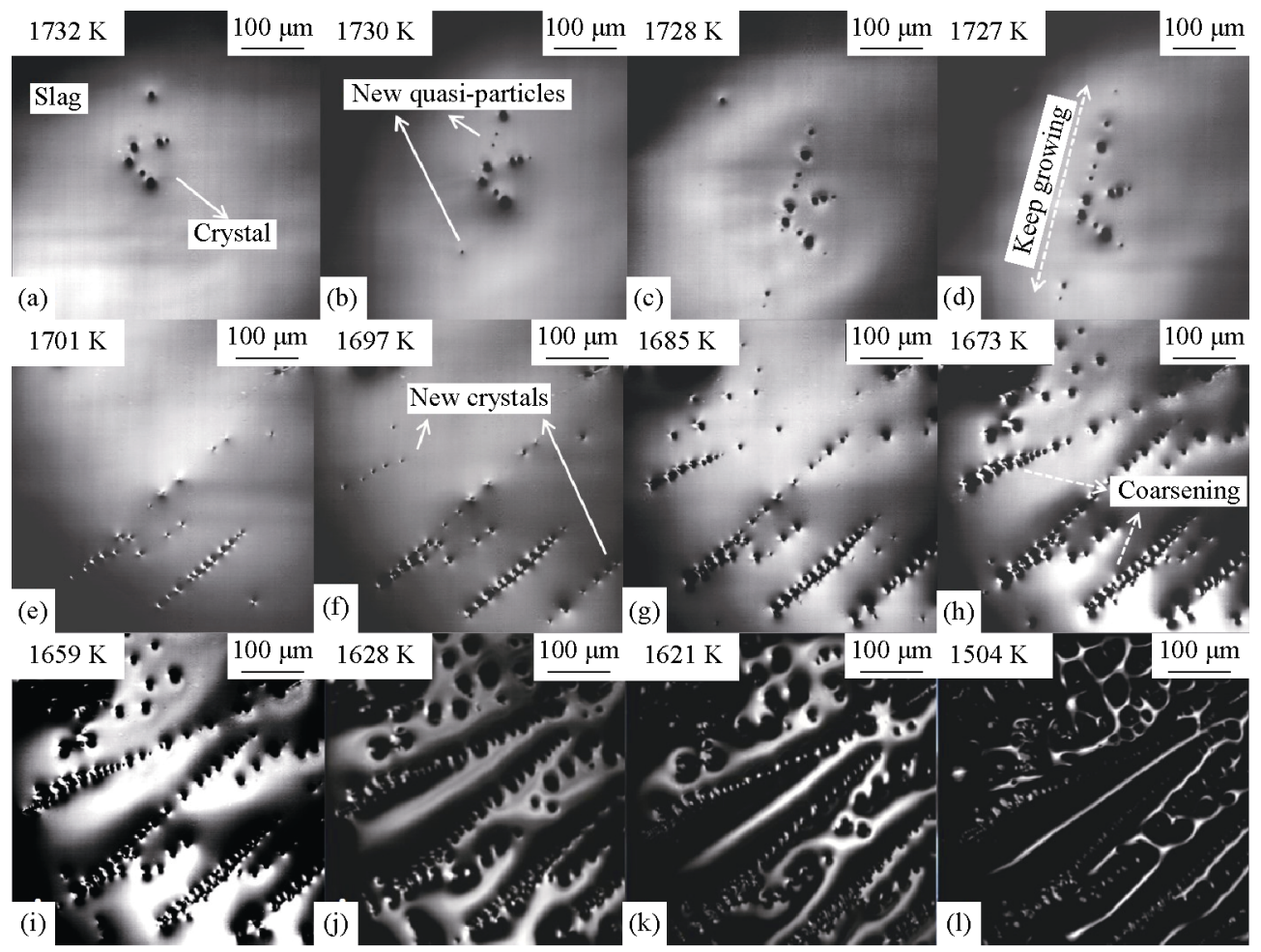

Fig. 4. CSLM images revealing the crystallization of slag at the cooling rate of $10 \mathrm{~K} / \mathrm{min}$.

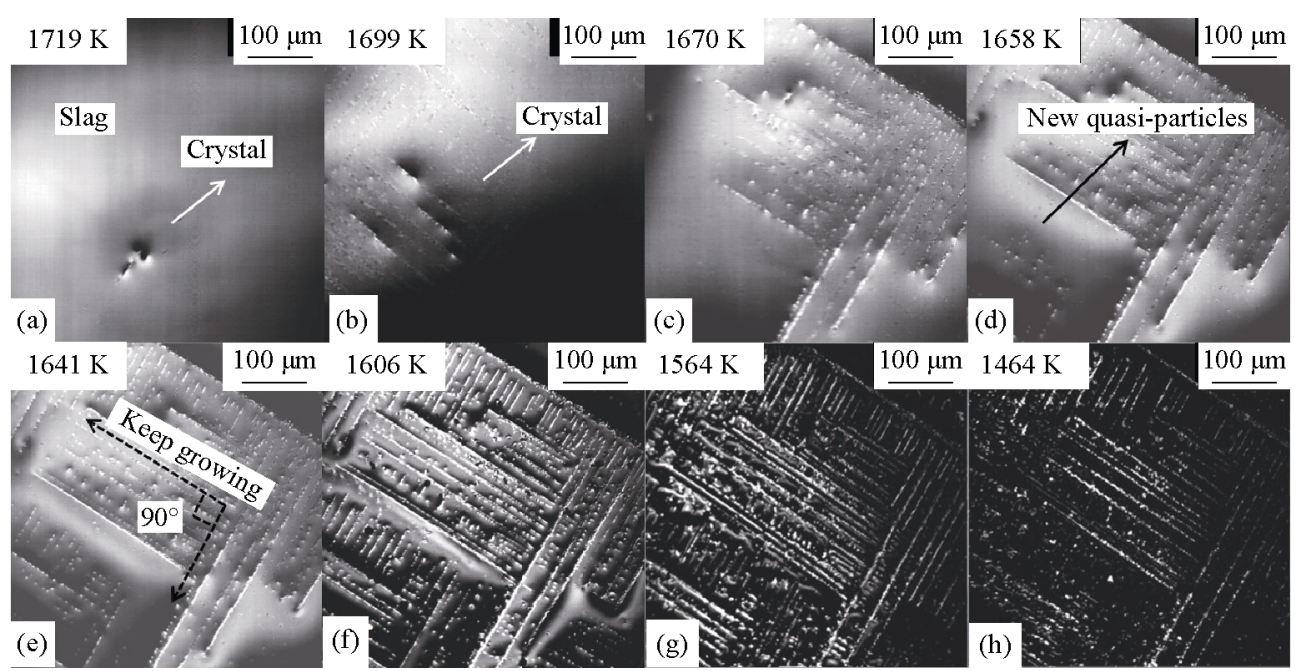

Fig. 5. CSLM images revealing the crystallization of slag at the cooling rate of $20 \mathrm{~K} / \mathrm{min}$.

a close orthogonal morphology with quasi-particles along the straight lines. With decrease in temperature, the crystals continue to grow along the orthogonal directions, such that the new quasi-particles are aligned successively. This leads to the formation of a closely spaced structure presumably made up of dendrites with quasi-particles at the dendritic tips (Figs. 5(b)-5(h)).

Similarly, at the cooling rate of $30 \mathrm{~K} / \mathrm{min}$, a single quasi-particle appears at $1717 \mathrm{~K}$ (Fig. 6(a)). The growth mode of the crystals is analogous to that observed at the cooling rate of $10 \mathrm{~K} / \mathrm{min}$ (Fig. 6(b)-6(h)).

On the other hand, at the cooling rate of $40 \mathrm{~K} / \mathrm{min}$, the first crystal appears at around $1687 \mathrm{~K}$, which subsequently streams away. Later on, three crystals drift into the viewing field at around $1637 \mathrm{~K}$ (Fig. 7(a)). The growth of the three crystals is such that the quasi-particles are aligned successively along straight lines. Intriguingly, the three big quasi-particles (1\#, 2\#, 3\#) form a regular triangular shaped crystal (as indicated by the symbol I in Fig. 7(a)), unlike the crystal morphologies obtained at lower cooling rates mentioned before. Furthermore, with decrease in temperature, the line formed by the quasi-particles of one crystal intersects with the biggest quasi-particle at almost $60^{\circ}$ (Fig. 7(d)), facilitating the formation of a snowflake morphology. 


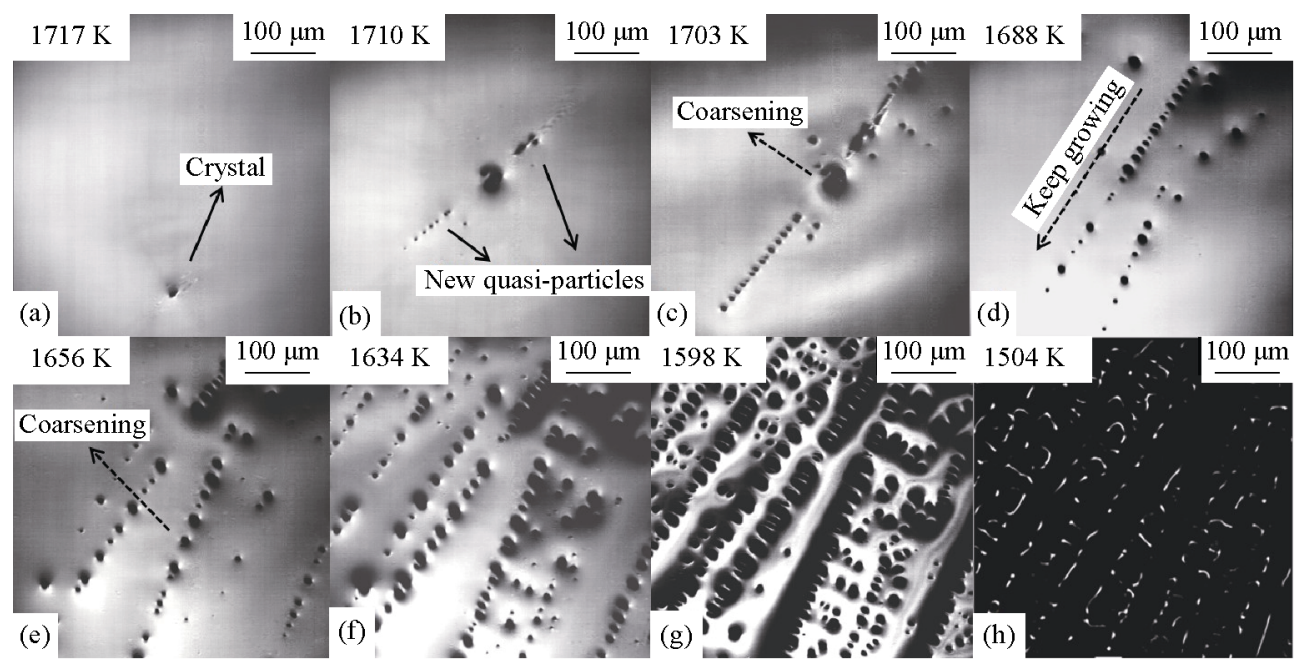

Fig. 6. CSLM images revealing the crystallization of slag at the cooling rate of $30 \mathrm{~K} / \mathrm{min}$.

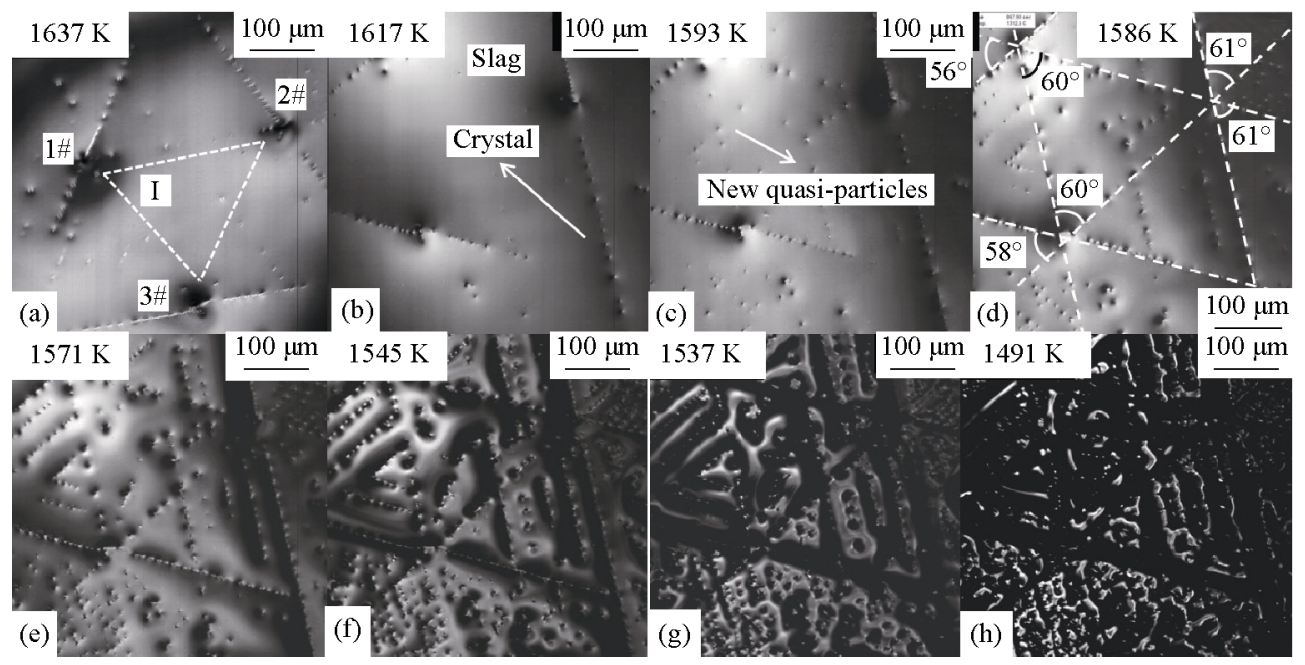

Fig. 7. CSLM images revealing the crystallization of slag at the cooling rate of $40 \mathrm{~K} / \mathrm{min}$.

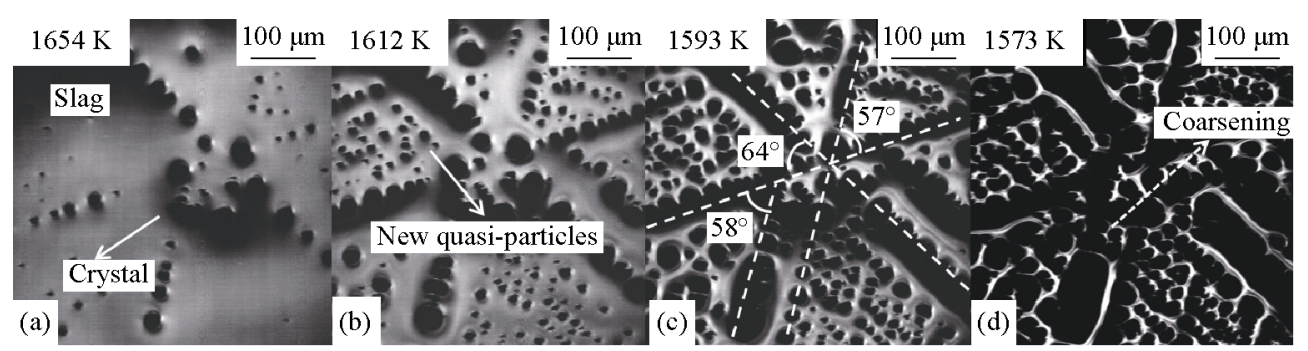

Fig. 8. CSLM images revealing the crystallization of slag at the cooling rate of $50 \mathrm{~K} / \mathrm{min}$.

Fig. 8 shows the crystal appearing in the viewing field at $1693 \mathrm{~K}$, corresponding to the cooling of $50 \mathrm{~K} / \mathrm{min}$. The crystal presents snowflake morphology, with an angle of $60^{\circ}$ between the six legs (Fig. 8(c)). The six legs of the snowflake separate the visible liquid phase into six sections. In each section, the new quasi-particles appear along the straight lines. With decrease in temperature, the crystal coarsens, followed by the gradual reduction of the liquid phase.
The melting point of the high-Ti-bearing slag is about 1723 K. During the CSLM experiment, the temperature at which the crystal first appears in the viewing field might not be the actual crystallization temperature. Rather, the primary phase might have been produced under the surface of liquid slag or outside the viewing field. Nevertheless, the trend shown in Fig. 9 indicates that the crystallization temperature decreases at higher cooling rates. In short, the higher the cooling rate, the higher the degree of supercooling is [20]. 


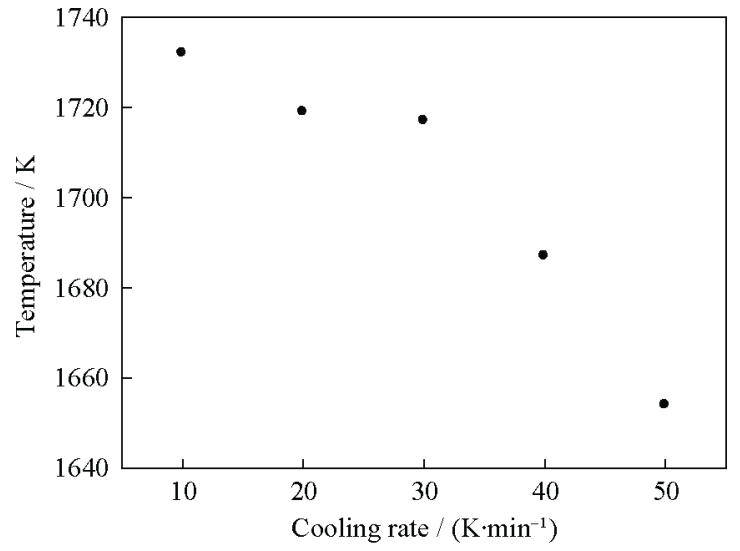

Fig. 9. Plot showing temperature at which crystals begin to appear in the slag surface at different cooling rates.

\subsection{SEM and XRD analyses}

Fig. 10 illustrates the XRD patterns of the samples cooled at different cooling rates. As can be seen from the diffraction patterns, the main crystalline phase in the samples is perovskite, which coexists with other phases such as $\mathrm{MgAl}_{2} \mathrm{O}_{4}$ and $\mathrm{CaMgSi}_{2} \mathrm{O}_{6}$. Besides, the XRD result reveals some amorphous peaks, indicating that some slag still remains in the glassy phase (without complete crystallization) under the current experimental conditions. Fig. 11 shows the BSE images of the polished surface of the slag samples after the CSLM experiments. As is seen, the crystals exhibit snowflake, dendritic, and orthogonal morphologies, similar to results observed in CSLM, which are the typical charac- teristics of the perovskite structure. In addition, the BSE images reveal that the crystals are denser, finer, with several branches, and smaller dendrite arm spacing, at higher cooling rates. Fig. 12 shows the elemental distribution of the polished surface of the slag sample cooled at the rate of 10 $\mathrm{K} / \mathrm{min}$. Fig. 13 shows the polished surface of the slag sample cooled at the cooling rate of $20 \mathrm{~K} / \mathrm{min}$. The corresponding chemical compositions of spots 1, 2, and 3 in Figs. 12 and 13 are summarized in Table 2. As evidenced from the results, the crystals mainly consist of $\mathrm{Ti}, \mathrm{Ca}$, and $\mathrm{O}$ with their atomic ratio close to $1: 1: 3$, suggesting that the crystals are perovskite. The other regions without distinct crystal morphology mainly contain $\mathrm{Ca}, \mathrm{Si}, \mathrm{Mg}, \mathrm{Al}$, and $\mathrm{O}$.

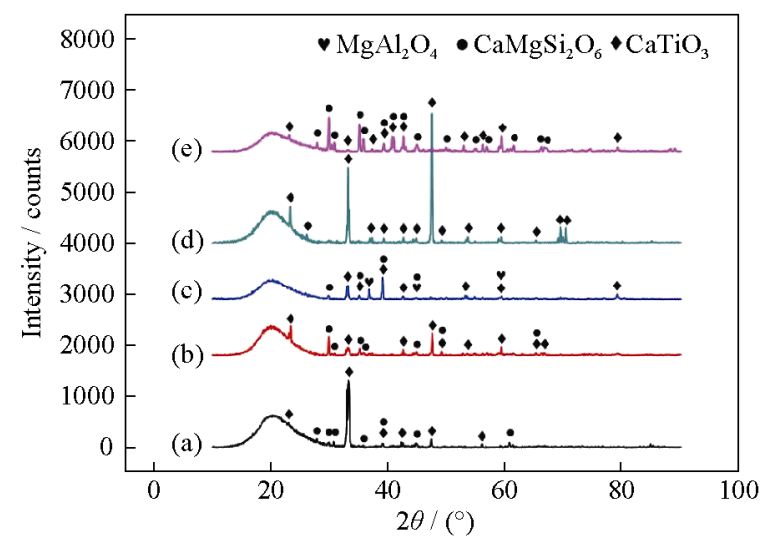

Fig. 10. XRD patterns of samples cooled at different cooling rates: (a) $10 \mathrm{~K} / \mathrm{min}$; (b) $20 \mathrm{~K} / \mathrm{min}$; (c) $30 \mathrm{~K} / \mathrm{min}$; (d) $40 \mathrm{~K} / \mathrm{min}$; (e) $50 \mathrm{~K} / \mathrm{min}$.

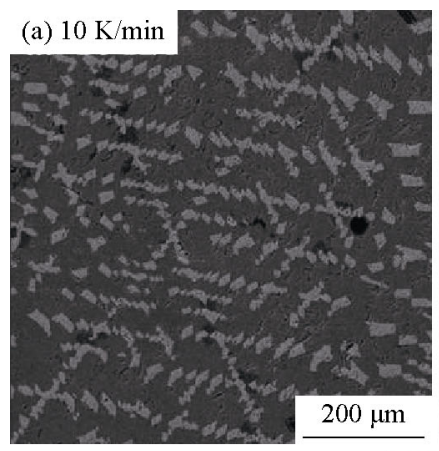

(d) $40 \mathrm{~K} / \mathrm{min}$

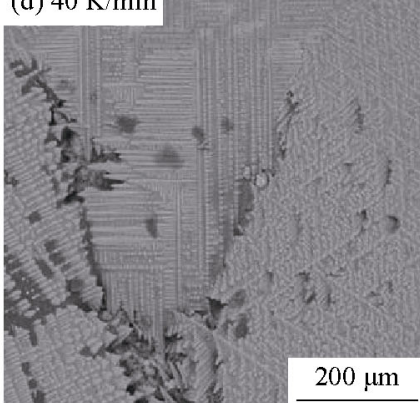

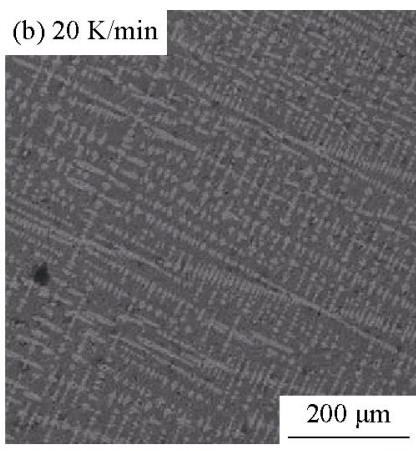

(c) $30 \mathrm{~K} / \mathrm{min}$

(e) $50 \mathrm{~K} / \mathrm{min}$
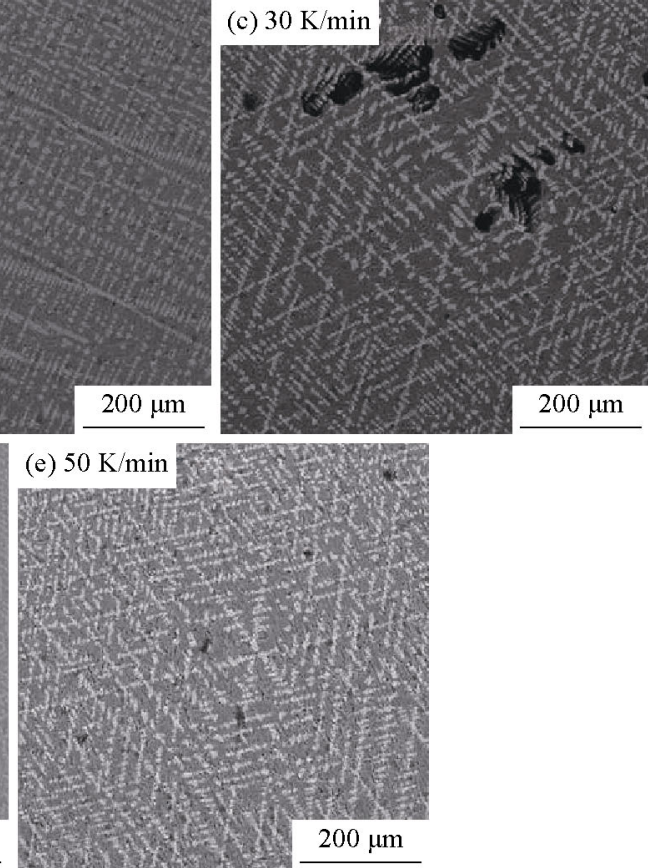

Fig. 11. BSE images of polished sample surfaces after the CSLM experiment. 


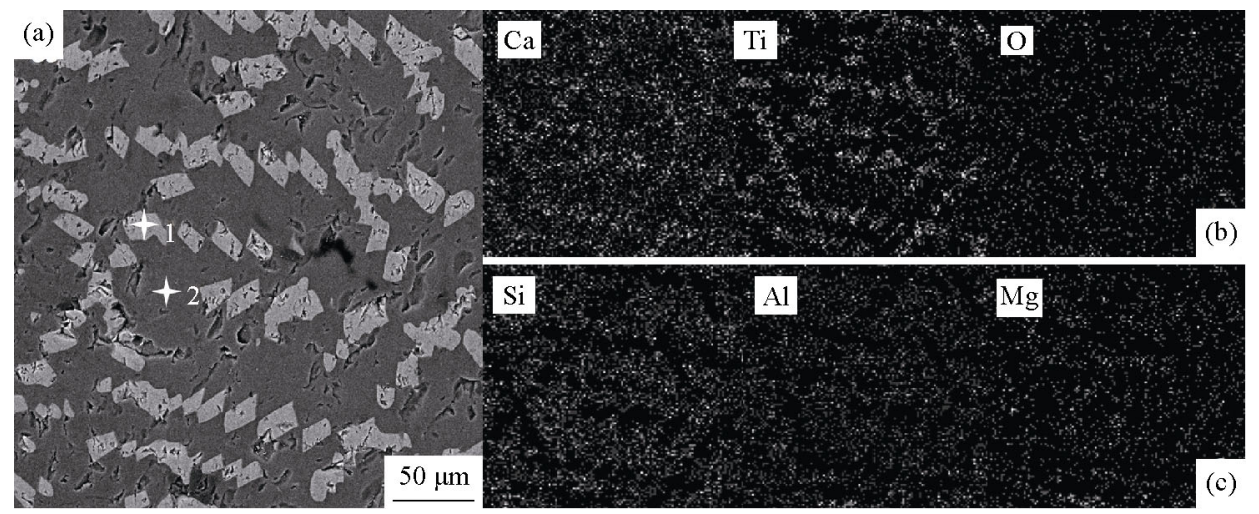

Fig. 12. BSE image (a) and EDS elemental mapping (b,c) of the slag sample cooled at the cooling rate of $10 \mathrm{~K} / \mathrm{min}$.

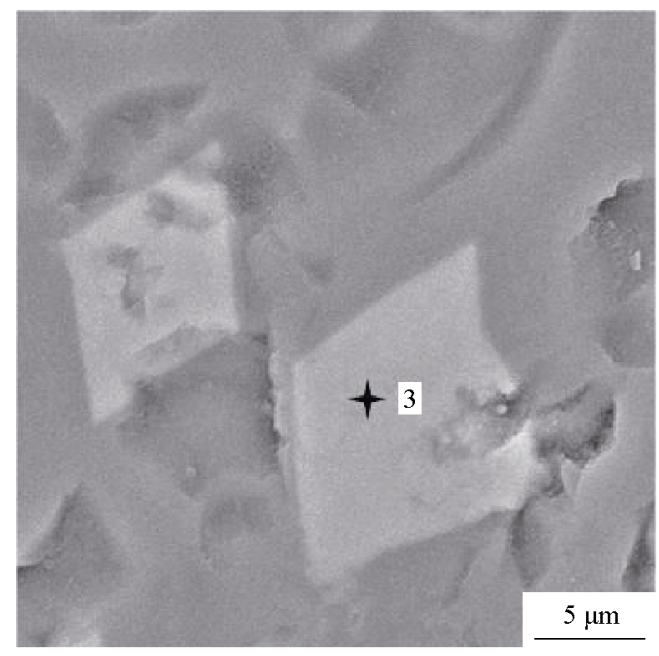

Fig. 13. BSE image of the perovskite section cooled at the cooling rate of $20 \mathrm{~K} / \mathrm{min}$.

Table 2. EDS spot scanning results of spots 1, 2, and 3 in Figs. 12 and 13

\begin{tabular}{crccccccc}
\hline $\begin{array}{l}\text { Spot } \\
\text { No. }\end{array}$ & \multicolumn{1}{c}{$\mathrm{Ti}$} & $\mathrm{Ca}$ & $\mathrm{Si}$ & $\mathrm{Al}$ & $\mathrm{Mg}$ & $\mathrm{O}$ & Total & $\begin{array}{c}x \text { in } \\
\mathrm{TiO}_{x}\end{array}$ \\
\hline 1 & 22.59 & 21.56 & $<0.01$ & $<0.01$ & $<0.01$ & 55.84 & 99.99 & 1.52 \\
2 & 3.16 & 10.45 & 17.68 & 9.47 & 5.79 & 53.45 & 100.00 & - \\
3 & 20.44 & 18.91 & $<0.01$ & $<0.01$ & $<0.01$ & 60.65 & 99.99 & 2.04 \\
\hline
\end{tabular}

\section{Discussion}

\subsection{Crystalline phase and growth of crystals}

To gain a comprehensive understanding of the crystallization process, the equilibrium phases of the Ti-bearing slag synthesized at different temperatures were calculated by using FactSage 6.3 (Fig. 14). According to the equilibrium phase diagram, the melting point of the slag is $1703 \mathrm{~K}$, and perovskite is the primary phase formed during the cooling of slag.

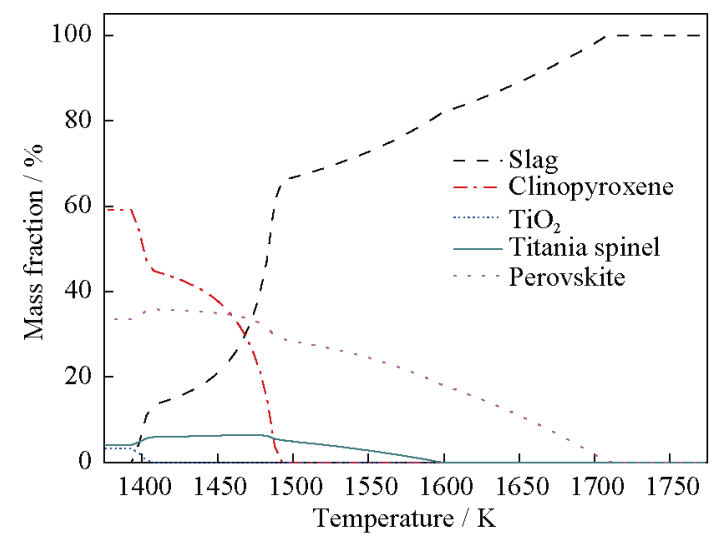

Fig. 14. Theoretical isothermal phase composition of the synthesized slag. Clinopyroxene: $\mathrm{CaMgSi}_{2} \mathrm{O}_{6}, \mathrm{CaAl}_{2} \mathrm{SiO}_{6}$, $\mathrm{CaMgAlSiO}_{6}$, and $\mathrm{CaAlSi}_{2} \mathrm{O}_{6}$; titania spinel: $\mathrm{MgAl}_{2} \mathrm{O}_{4}$; perovskite: $\mathrm{Ca}_{2} \mathrm{Ti}_{2} \mathrm{O}_{6}$ and $\mathrm{Ca}_{2} \mathrm{Ti}_{2} \mathrm{O}_{5}$.

Correlating the analytical and calculated results, it can be concluded that the crystals observed in the CSLM experiment are perovskite. Other phases reported in XRD analysis and theoretical calculations were not observed, probably because the amounts are too small to be detected or the other phases do not have clear crystal morphology.

According to the experimental results, the perovskite crystals grow by the successive appearance of quasi-particles along straight lines, which further extended in certain directions to form various dendritic morphologies, including fork, orthogonal, and snowflake shapes. The crystals are first produced under the surface of liquid slag, and the quasi-particles aligned on the slag surface are the dendritic tips that come from the same dendrite arm. The crystals observed in the BSE images are the sections of the dendrites.

\subsection{Effect of cooling rate on the structure of perovskite}

Results obtained in this study indicate that the morphology and growth of perovskite is closely related to cooling rate. Figs. 4-8 indicate that the dendritic arms cross obli- 
quely at cooling rates of 10 and $30 \mathrm{~K} / \mathrm{min}$, while the dendritic arms are orthogonal at the cooling rate of $20 \mathrm{~K} / \mathrm{min}$, and intersect at an angle of $60^{\circ}$ at the cooling rates of 40 and $50 \mathrm{~K} / \mathrm{min}$. The observed variations in the microstructure clearly indicate that the crystal structure of perovskite changes with cooling rate.

The chemical formula of perovskite is $\mathrm{CaTiO}_{3}$, in which the two cations $\mathrm{Ca}$ and $\mathrm{Ti}$ are of very different sizes. And, $\mathrm{O}$ is the anion that bonds to both the cations. The ideal cubic-symmetry structure is characterized by the $\mathrm{Ca}$ cations in 6-fold coordination, surrounded by an octahedron of anions, while the Ti cation exists in 12-fold cubo-octahedral coordination. This structural arrangement is valid only when all the $\mathrm{Ti}$ ions in the crystal exist in the $\mathrm{Ti}^{4+}$ state. When some $\mathrm{Ti}^{3+}$ ions are present in the system, there is a corresponding reduction in the number of $\mathrm{O}^{2-}$ ions in the lattice. Consequently, the lattice distorts slightly to form several lower-symmetry distorted versions, such as orthorhombic, tetragonal, or trigonal structures [21].

If perovskite has an ideal cubic-symmetry structure, then the crystal morphology is an isometric dendrite with orthogonal intersection of dendritic arms, as that observed at the cooling rate of $20 \mathrm{~K} / \mathrm{min}$. On the other hand, oblique crossing of dendritic arms suggests the orthorhombic structure of perovskite at the cooling rates of 10 and $30 \mathrm{~K} / \mathrm{min}$. For the cooling rates of 40 and $50 \mathrm{~K} / \mathrm{min}$, the crystals have a snowflake shape, suggesting the hexagonal structure of perovskite, as shown in Fig. 15.

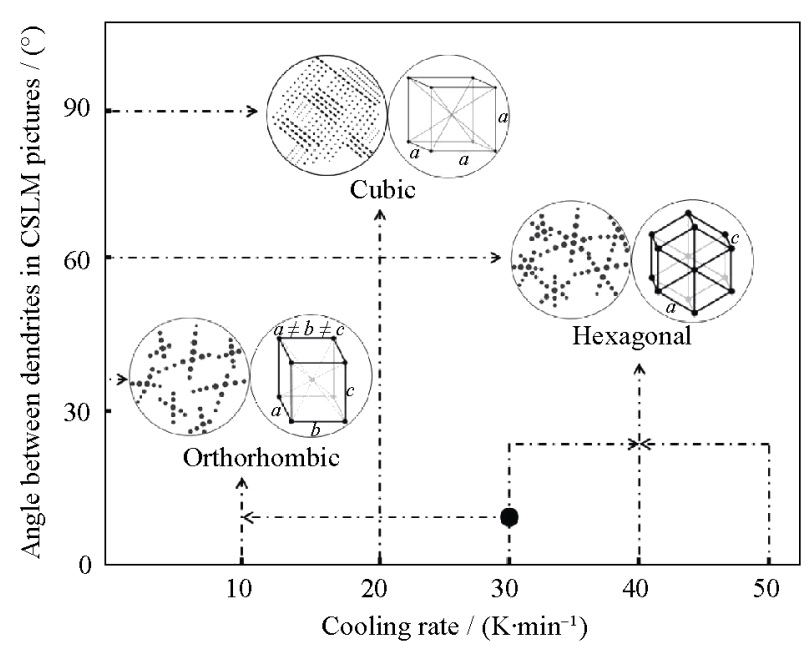

Fig. 15. Surface morphology and structure of perovskite formed at different cooling rates.

According to the equilibrium phase diagram obtained using FactSage, perovskite is modeled as a solid solution of $\mathrm{Ca}_{2} \mathrm{Ti}_{2} \mathrm{O}_{6}$ and $\mathrm{Ca}_{2} \mathrm{Ti}_{2} \mathrm{O}_{5}$, wherein Ti exists in both $\mathrm{Ti}^{4+}$ and $\mathrm{Ti}^{3+}$ states. Comparing the atomic percentage of $\mathrm{Ti}$ and $\mathrm{O}$ elements in perovskite crystals at cooling rates of 10 and 20 $\mathrm{K} / \mathrm{min}$ shown in Table 2, it is supposed that the perovskite is composed of $\mathrm{TiO}_{2}$, when the slag was cooled at the rate of $20 \mathrm{~K} / \mathrm{min}$. On the other hand, the crystals are partly formed by $\mathrm{Ti}_{2} \mathrm{O}_{3}$, instead of $\mathrm{TiO}_{2}$, at the cooling rate of $10 \mathrm{~K} / \mathrm{min}$. The crystal structure with $\mathrm{TiO}_{2}$, which contains full amount of $\mathrm{O}^{2-}$, makes the ideal perovskite cubic structure with the chemical formula of $\mathrm{Ca}_{2} \mathrm{Ti}_{2} \mathrm{O}_{6}$. However, in the presence of $\mathrm{Ti}_{2} \mathrm{O}_{3}$ in perovskite with the formula $\mathrm{Ca}_{2} \mathrm{Ti}_{2} \mathrm{O}_{5}$, the cubic structure tends to distort because of the deficiency of $\mathrm{O}^{2-}$ in the system. To further investigate the formation of perovskite, we calculated the phase diagram of $\mathrm{CaO}-\mathrm{Ti}_{2} \mathrm{O}_{4}-\mathrm{Ti}_{2} \mathrm{O}_{3}-$ $\mathrm{SiO}_{2}-\mathrm{MgO}-\mathrm{Al}_{2} \mathrm{O}_{3}$ with a fixed amount of $\mathrm{SiO}_{2}-\mathrm{MgO}-$ $\mathrm{Al}_{2} \mathrm{O}_{3}$ at $1673 \mathrm{~K}$ (Fig. 16). Results indicate that the perovskite can form in any proportion of $\mathrm{Ti}_{2} \mathrm{O}_{3}$ and $\mathrm{TiO}_{2}$ under the given conditions. Accordingly, the distortion of the perovskite structure can be attributed to the deficiency of $\mathrm{O}^{2-}$.

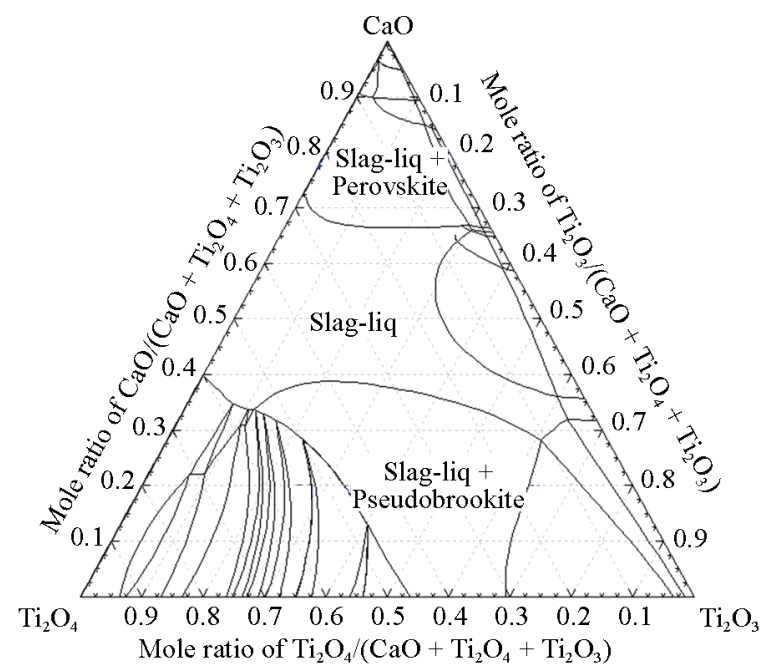

Fig. 16. Equilibrium phase diagram of $\mathrm{CaO}-\mathrm{Ti}_{2} \mathrm{O}_{4}-\mathrm{Ti}_{2} \mathrm{O}_{3}-$ $\mathrm{SiO}_{2}-\mathrm{MgO}-\mathrm{Al}_{2} \mathrm{O}_{3}$ with a fixed amount of $\mathrm{SiO}_{2}-\mathrm{MgO}-\mathrm{Al}_{2} \mathrm{O}_{3}$ at $1673 \mathrm{~K}$ and $101 \mathrm{kPa}$. The mole fraction: $\mathrm{SiO}_{2} / \mathrm{Z}=\mathbf{0 . 6 6 3}$, $\mathrm{MgO} / \mathrm{Z}=0.302, \mathrm{Al}_{2} \mathrm{O}_{3} / \mathrm{Z}=0.209$, where $\mathrm{Z}=\mathrm{CaO}+\mathrm{Ti}_{2} \mathrm{O}_{4}+$ $\mathrm{Ti}_{2} \mathrm{O}_{3}$.

In principle, the existence of $\mathrm{Ti}_{2} \mathrm{O}_{3}$ can be related to the oxygen potential condition. To further understand the effect of oxygen potential on the transformation from $\mathrm{Ti}^{4+}$ to $\mathrm{Ti}^{3+}$ states, we calculated the equilibrium phases of the slag with the addition of $\mathrm{H}_{2}$ using FactSage. As can be seen from Fig. 17(a), the perovskite phase can also be modeled as a solution of $\mathrm{Ca}_{2} \mathrm{Ti}_{2} \mathrm{O}_{6}$ and $\mathrm{Ca}_{2} \mathrm{Ti}_{2} \mathrm{O}_{5}\left(\mathrm{Ti}^{4+}\right.$ and $\left.\mathrm{Ti}^{3+}\right)$ under reducing conditions at $1773 \mathrm{~K}$. Besides, the results indicate that the amount of perovskite as well as the fraction of $\mathrm{Ti}^{3+}$ increase obviously with increase in reducing conditions (simulated by the $\mathrm{H}_{2}$ addition). This implies that the presence of $\mathrm{Ca}_{2} \mathrm{Ti}_{2} \mathrm{O}_{5}$ could lead to an increase in the crystalliza- 
tion temperature of perovskite in the slag. As can be seen from Fig. 17(b), mild reducing conditions can increase $\mathrm{Ti}^{3+}$ in the existing perovskite. In the present study, the pre-melting of the slag and the CSLM experiments were performed under argon atmosphere, and hence the actual oxygen potential state could not be identified. Given the fact

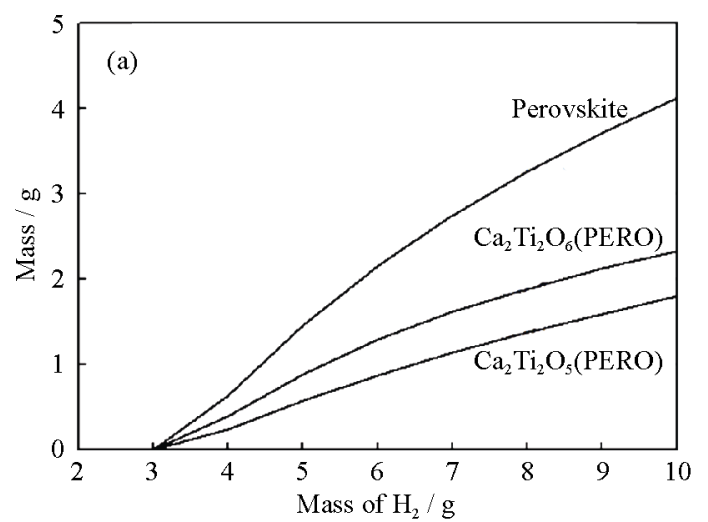

that the mild reducing conditions lead to the generation of $\mathrm{Ti}^{3+}$, it is reasonable to assume the existence of $\mathrm{Ca}_{2} \mathrm{Ti}_{2} \mathrm{O}_{5}$. Besides, the XRF analysis of the synthesized slag indicates the formation of $\mathrm{MoO}_{3}$ during the pre-melting process. This might change the oxygen potential state, according to the reaction $6 \mathrm{TiO}_{2}+\mathrm{Mo}=3 \mathrm{Ti}_{2} \mathrm{O}_{3}+\mathrm{MoO}_{3}$.

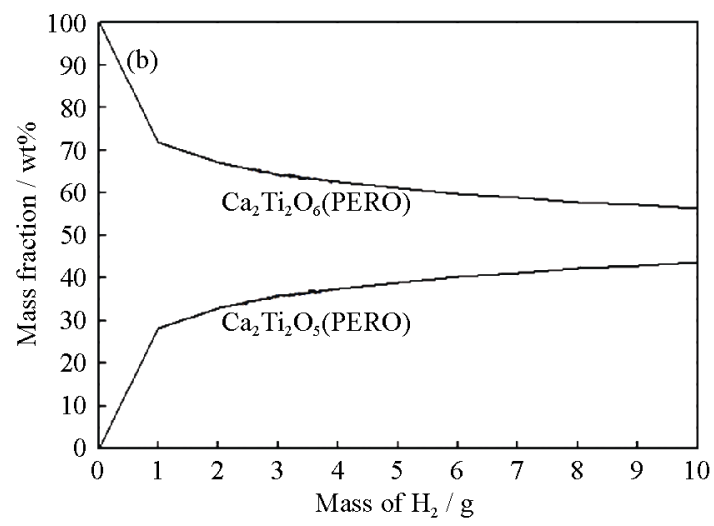

Fig. 17. Mass change of perovskite, $\mathrm{Ca}_{2} \mathrm{Ti}_{2} \mathrm{O}_{6}$, and $\mathrm{Ca}_{2} \mathrm{Ti}_{2} \mathrm{O}_{5}$ in the designed slag $23 \mathrm{TiO}_{2}+28.8 \mathrm{CaO}+26.2 \mathrm{SiO}_{2}+14 \mathrm{Al}_{2} \mathrm{O}_{3}+8 \mathrm{MgO}$ (wt\%) under reducing conditions at $1773 \mathrm{~K}$ (with the addition of $\mathrm{H}_{2}$ ) (PERO is perovskite): (a) mass change of perovskite, $\mathrm{Ca}_{2} \mathrm{Ti}_{2} \mathrm{O}_{6}$, and $\mathrm{Ca}_{2} \mathrm{Ti}_{2} \mathrm{O}_{5}$ with the addition of $\mathrm{H}_{2} ;$ (b) mass fraction change of $\mathrm{Ca}_{2} \mathrm{Ti}_{2} \mathrm{O}_{6}$ and $\mathrm{Ca}_{2} \mathrm{Ti}_{2} \mathrm{O}_{5}$ in generated perovskite with the addition of $\mathbf{H}_{2}$.

On the other hand, at higher cooling rates, the perovskite structure distortion becomes more obvious. In principle, higher cooling rates are associated with a higher degree of supercooling, which influences the diffusion rate of ions in the slag. In the high Ti-bearing slag, $\mathrm{Ti}$ exists as $\mathrm{TiO}_{4}{ }^{4-}$ and acts as a network builder, similar to $\mathrm{SiO}_{4}{ }^{4-}$. When the cooling rate is high, the diffusion rate of $\mathrm{TiO}_{4}{ }^{4-}$ may be lower than the anion group formed of $\mathrm{Ti}^{3+}$, thereby promoting the formation of $\mathrm{Ca}_{2} \mathrm{Ti}_{2} \mathrm{O}_{5}$. The presence of more perovskites with $\mathrm{O}^{2-}$ deficiency leads to more distortion of its structure. As a result, the structure and morphology of the dendritic perovskite change with the cooling rate.

\section{Conclusions}

(1) Perovskite is the primary phase formed during the crystallization of high Ti-bearing slag $\left(\mathrm{TiO}_{2}=23 \mathrm{wt} \%\right)$. The perovskite dendrites precipitate under the slag surface, with the dendritic tips growing toward the slag surface. On the slag surface, perovskite grows via the successive production of quasi-particles along straight lines. They extend in certain directions, resulting in the formation of different dendrite morphologies, including fork, orthogonal, and snowflake shapes.

(2) The morphology and structure of perovskite vary as a function of cooling rate. The dendritic arms of the perovskite cross obliquely at the cooling rates of 10 and 30
$\mathrm{K} / \mathrm{min}$, while the dendritic arms cross orthogonally at the cooling rate of $20 \mathrm{~K} / \mathrm{min}$, and intersect at an angle of $60^{\circ}$ at the cooling rates of 40 and $50 \mathrm{~K} / \mathrm{min}$. The three crystal morphologies respectively correspond to orthorhombic, cubic, and hexagonal crystal structures of perovskite.

(3) The observed change in the perovskite structure is probably caused by the following reasons. (i) Under the given experimental conditions, $\mathrm{Ti}_{2} \mathrm{O}_{3}$ exists in the slag, resulting in perovskite with formula of $\mathrm{Ca}_{2} \mathrm{Ti}_{2} \mathrm{O}_{5}\left(\mathrm{Ti}^{3+}\right)$. Besides, corresponding $\mathrm{O}^{2-}$ deficiency leads to the distortion of the ideal cubic structure of $\mathrm{Ca}_{2} \mathrm{Ti}_{2} \mathrm{O}_{6}\left(\mathrm{Ti}^{4+}\right)$. (ii) Cooling rate affects the diffusion rate of $\mathrm{Ti}^{4+}$ and $\mathrm{Ti}^{3+}$, leading to different proportions of $\mathrm{Ca}_{2} \mathrm{Ti}_{2} \mathrm{O}_{5}$ and $\mathrm{Ca}_{2} \mathrm{Ti}_{2} \mathrm{O}_{6}$ in the perovskite, implying different degrees of deformation.

\section{Acknowledgements}

This work was financially supported by the National Natural Science Foundation of China (No. 51090383) and the Fundamental Research Funds for the Central Universities of China (No. CDJZR12130049). The authors would like to express their sincere thanks to Dr. David G.C. Robertson (Professor Emeritus of Metallurgical Engineering, Department of Materials Science and Engineering, Missouri University of Science and Technology, E-mail: davidrob@ umr.edu) for his insightful suggestions and guidance throughout this work. 


\section{References}

[1] T.P. Lou, Y.H. Li, L.S. Li, and Z.T. Sui, Study on kinetics of perovskite phase precipitate in slag bearing titanium, J. Chin. Ceram. Soc., 28(2000), No. 3, p. 255.

[2] Y.C. Wu, L.Y. Song, Y. Li, Y. Li, G.H. Li, and Z.X. Zheng, Preparation and photocatalystic activity of Ce-doped $\mathrm{TiO}_{2}$ nanoparticles, J. Synth. Cryst., 37(2008), No. 2, p. 427.

[3] H. Yang, X.X. Xue, L. Zuo, and Z.D. Yang, Photocatalytic degradation of brilliant red $\mathrm{X}-3 \mathrm{~B}$ with blast-furnace slag containing titania and rare earth oxides, J. Chin. Ceram. Soc., 31(2003), No. 9, p. 896.

[4] S.L. Liu, S.L. Yang, and S.Z. Gao, Technical progress and development trend of extracting titanium from Panzhihua titanium-bearing blast furnace slag, Panzhihua Sci-Tech Inf., 31(2006), No. 4, p. 10.

[5] X.W. Sun, J.T. Zhang, Z.Y. Yang, T.C. You, and Y. Liu, Development of high titaniferous blast-furnace slag brick, New Build. Mater., (2003), No. 3, p. 5.

[6] P. Wang, B.Q. Han, Y.L. Han, C.M. Ke, and N. Li, Research on hydration capability of Panzhihua Iron and Steel CO. BF slag after extracting silicon-titanium alloy, Bull. Chin. Ceram. Soc., 27(2008), No. 6, p. 1208.

[7] Y. Xiong, B. Liang, and C. Li, Extraction and separation of titanium from air-cooled Ti-bearing blast furnace slag, Chin. J. Process Eng., 8(2008), No. 6, p. 1092.

[8] X.H. Liu and Z.T. Sui, Leaching of Ti-bearing blast furnace slag by pressuring, Chin. J. Nonferrous Met., 12(2002), No. 6, p. 1281.

[9] X.H. Li and J.T. Pu, The latest developments of integrated utilization on Panzhihua high titanium-bearing BF slag, Iron Steel Vanadium Titanium, 32(2011), No. 2, p. 10.

[10] Z.Z. Guo, T.P. Lou, L. Zhang, L.N. Zhang, and Z.T. Sui, Precipitation and growth of perovskite phase in titanium bearing blast furnace slag, Acta Metall. Sin. Engl. Lett., 20(2007), No. 1, p. 9.

[11] J. Li, Z.T. Zhang, L.L. Liu, W.L. Wang, and X.D. Wang, Influence of basicity and $\mathrm{TiO}_{2}$ content on the precipitation behavior of the Ti-bearing blast furnace slags, ISIJ Int., 53(2013), No. 10, p. 1696.
[12] J. Li, X.D. Wang, and Z.T. Zhang, Crystallization behavior of rutile in the synthesized Ti-bearing blast furnace slag using single hot thermocouple technique, ISIJ Int., 51(2011), No. 9, p. 1396.

[13] L. Zhang, L.N. Zhang, M.Y. Wang, G.Q. Li, and Z.T. Sui, Recovery of titanium compounds from molten Ti-bearing blast furnace slag under the dynamic oxidation condition, Miner. Eng., 20(2007), No. 7, p. 684.

[14] L. Zhang, L.N. Zhang, M.Y. Wang, G.Q. Li, and Z.T. Sui, Precipitation selectivity of perovskite phase from Ti-bearing blast furnace slag under dynamic oxidation conditions, J. Non Cryst. Solids, 353(2007), No. 22-23, p. 2214.

[15] Y.H. Li, T.P. Lou, Y.H. Xia, and Z.T. Sui, Kinetics of non-isothermal precipitation process of the perovskite phase in $\mathrm{CaO}-\mathrm{TiO}_{2}-\mathrm{SiO}_{2}-\mathrm{Al}_{2} \mathrm{O}_{3}-\mathrm{MgO}$ system, J. Mater. Sci., 35(2000), No. 22, p. 5635.

[16] M.Y. Wang, L. Zhang, L.N. Zhang, and Z.T. Sui, Characteristics change of Ti-bearing molten blast furnace slag under dynamic oxidation condition, Nonferrous Met., 60(2008), No. 2, p. 59.

[17] M.L. Hu, L. Liu, X.W. Lv, C.G. Bai, and S.F. Zhang, Crystallization behavior of perovskite in the synthesized high-titanium-bearing blast furnace slag using confocal scanning laser microscope, Metall. Mater. Trans. B, 45(2014), p. 76.

[18] H.P. Joo, G.P. Jin, J.M. Dong, E.L. Young and Y.B. Kang, In situ observation of the dissolution phenomena of $\mathrm{SiC}$ particle in $\mathrm{CaO}-\mathrm{SiO}_{2}-\mathrm{MnO}$ slag, J. Eur. Ceram. Soc., 30(2010), No. 15 , p. 3181.

[19] J. Liu, M. Guo, P.T. Jones, F. Verhaeghe, B. Blanpain, and P. Wollants, In situ observation of the direct and indirect dissolution of $\mathrm{MgO}$ particles in $\mathrm{CaO}-\mathrm{Al}_{2} \mathrm{O}_{3}-\mathrm{SiO}_{2}$-based slags, $J$. Eur. Ceram. Soc., 27(2007), No. 4, p. 1961.

[20] W. Kurz and D.J. Fisher, Fundamentals of Solidification, Translated by J.G. Li and Q.D. Hu, Higher Education Press, Beijing, 2013, p. 116.

[21] S. Dutch, Natural and Applied Sciences [R/OL], University of Wisconsin - Green Bay, http://www.uwgb.edu/dutchs/Petrology/Perovskite\%20Structure.HTM, created 22 Sept. 1997, last update 19 Jan. 2012. 